\title{
Pesquisa artística, conhecimento musical e a crise da contemporaneidade
}

\author{
Rubén López Cano \\ Escola Superior de Música de Catalunya - ESMUC
}

\section{Introdução}

A pesquisa artística situa-se no vértice de vários pontos críticos da cultura contemporânea. ${ }^{1}$ Entre estes, encontram-se os seguintes:

- A remodelação do sistema educacional no seu conjunto, que vai desde a emergência de novas tecnologias pedagógicas até a privatização e mercantilização da educação em todos os seus níveis.

- As discussões sobre o papel da educação, simplesmente como espaço de instrução prática para o trabalho remunerado ou como atividade holística, ampla, que busca a formação integral de sujeitos críticos, pensante, livres e capazes de transformar a sociedade.

- O papel da arte na sociedade como fator de elevação existencial, como atividade de ócio ou como insumo econômico das industrias turísticas e culturais.

- O papel dos artistas em propor novos conceitos para os problemas das sociedades contemporâneas e sua capacidade de oferecer soluções alternativas, ou pelo menos, de propor novas perguntas, baseadas em modos de pensamento não exclusivamente racionais.

- Os limites epistêmicos das ciências convencionais para proporcionar um conhecimento do mundo efetivo na compreensão da existência humana, etc.

\footnotetext{
${ }^{1}$ A pesquisa artística como atividade desenvolvida nos centros de ensino superior é extremamente contraditória. Para suas definições e discussões ver López-Cano e San Cristóbal (López-Cano e San Cristóbal 2014).
} 
A pesquisa artística no âmbito musical apresenta três problemas fundamentais. Inicialmente, a problemática inserção das artes no contexto das instituições de educação superior junto com a adaptação de suas peculiaridades às exigências acadêmico-administrativas das universidades. O segundo problema tem relação com a crise própria da música erudita ocidental (um público que envelhece ao mesmo tempo que diminui, sua crise de representatividade como um dos pilares da cultura ocidental; sua estagnação num repertorio canônico e fechado; seus obsoletos rituais performáticos ancorados numa cultura pré-digital e préaudiovisual pouco atrativas para a maioria dos espectadores contemporâneos. Definitivamente, parece se sufocar sob o peso da sua própria tradição). $\underline{0}$ terceiro problema é o da academização da música popular e da sua inserção nos programas de formação superior.

Em cada um destes problemas, o papel da pesquisa artística em música é intermitente pois, em certas ocasiões oferece respostas aos desafios (com diferente grau de êxito), entretanto, em outros, unicamente aprofunda a sua crise.

Na primeira parte do presente texto estabelecemos as características do-modelo de pesquisa artística que decidimos adotar, para distingui-lo de outras atividades de pesquisa similares que também serão discutidas. Posteriormente, analisaremos diversos elementos característicos da produção de conhecimento no contexto da pesquisa científica desenvolvida pelos intérpretes musicais nas instituições de educação superior. Indicaremos, especificamente, em que consistem seus objetos de estudo mais comuns e o suporte ou formato da sua produção (discursos, ações e objetos artísticos). Na última parte, abordaremos os tipos de conhecimentos que são produzidos nestas pesquisas, entre o que é possível de ser expressado por meios verbais e as dificuldades de representação do pensamento emocional, analógico, empático ou sensível. Tentaremos ir além de oposições, tais como conceitual/não conceitual, verbal/pré-verbal ou lógico/intuitivo para melhor compreensão da pesquisa artística como assunto do conhecimento e dos desafios que esta pesquisa apresenta à episteme musical. 


\section{Uma noção de pesquisa artística em música}

A pesquisa artística é, por definição, um processo de produção de conhecimento a partir da experiência prática. Alguns autores insistem que a atividade artística é produtora de conhecimento e que este é transmitido por seus próprios meios através das obras. Devido a isto, dizem, toda criação artística deve ser considerada como pesquisa e, portanto, deve ser avaliada e pontuada como tal pelas instituições educativas (Haseman, 2006; Smith e Dean, 2009). Eu chamo este processo de homologação. Outra corrente de pensamento defende a especificidade da pesquisa artística como uma atividade distinta da criação ou pesquisa acadêmica. Um pensamento contrário a esta última postura, considera que existe uma tensão e inclusive uma contraposição entre criação e pesquisa: a criação se apresenta como forma privilegiada de produção na arte, diferentemente do trabalho de "pesquisa" que os artistas podem realizar para sua criação; nega tanto as práticas de pesquisa articuladas às práticas artísticas, quanto a capacidade criadora dos cientistas (Asprilla, 2014).

Não questiono que as obras de arte sejam entidades de conhecimento por direito próprio e que a atividade estética seja em si mesma outra maneira de conhecerestar no mundo. ${ }^{2}$ Tampouco ponho em dúvida a dimensão criativa e estética da pesquisa científica ou social, nem a "pesquisa" que realizam muitos artistas durante seus processos criativos. ${ }^{3}$ Mas, creio que existe um problema de ambiguidade com o conceito de pesquisa. Coloco um exemplo. Todos os dias ao dar aulas, "examino" a minha mochila para achar o pen drive onde levo os materiais das aulas. Entretanto, em algumas ocasiões, examino meus alunos para avaliar seu aproveitamento nas minhas disciplinas. Fica evidente a diferença de significado no emprego do mesmo verbo: "examinar" e examinar. No primeiro caso, estou utilizando o verbo na sua acepção coloquial, enquanto no segundo, me refiro a uma atividade acadêmica específica, que cumpre certos requisitos institucionais em termos de formato, planejamento, operação e avaliação.

É verdade que não existe um consenso entre as instituições sobre o que é a pesquisa artística. Entretanto, dentre as suas múltiplas interpretações, neste

2 Em 1750 Baumgarten já tinha definido a estética como gnosiologia inferior ou Ciência do conhecimento sensível.

3 O extraordinário pensador e tecnólogo Abraham Moles já falava, no final dos anos 1950, da dimensão estética de certas decisões que tomam os cientistas durantes as suas pesquisas (Moles 1957 [1986]). 
texto farei referência a uma noção técnica de pesquisa diferente da definição coloquial de "pesquisa" à qual se refere a indagação que realiza qualquer pessoa que busca alguma informação. Por pesquisa artística refiro-me a uma atividade acadêmica formal, praticada em instituições de educação artística superior, distinta em propósitos, princípios, métodos e resultados à criação, ensino ou gestão artística e à investigação acadêmica universitária, embora compartilhe elementos comuns. Elas são realizadas por estudantes prestes a concluir seus cursos com o objetivo de avaliar algumas das competências profissionais adquiridas ou professores que desejam realizar contribuições significativas para o desenvolvimento profissional, para além da produção da obra artística. ${ }^{4}$

A pesquisa artística à qual eu me refiro, não questiona os processos criativos no trabalho científico, nem os processos reflexivo-investigativos dos artistas. Tampouco pretende repensar ou reformular a distinção histórica entre as áreas científicas e artísticas, nem descrever seus traços ontológicos de identidade. Simplesmente, de maneira mais modesta, propõe caminhos de trabalho distintos para o desenvolvimento e a transformação crítica de um campo profissional específico: a arte. Por outro lado, nem tudo na arte é criação. Existe uma grande quantidade de reprodução acrítica de técnicas, cânones estéticos e clichês. Também, a arte é transmissora de valores, discursos e princípios culturais destinados a controlar os sujeitos ou desagregar dogmas culturais. Historicamente, por exemplo, a música e a dança tiveram um papel importante no exercício do biopoder, promovendo a hétero-normatividade patriarcal hegemônica, ao colaborar na construção de corpos arquetípicos do masculino e do feminino (López-Cano, 2008). Também colabora na construção de subjetividades hegemônicas, através da unificação do gosto por meio de cânones dogmáticos ou músicas e danças "nacionais" [músicas y bailes identitarios]. A arte é também cenário de disputas pelo poder econômico e simbólico, revelando a impiedosa organização e hierarquia de um grupo e a ascensão e o controle de instituições reguladoras, econômica e politicamente situadas. A pesquisa artística também pode se ocupar da crítica e reversão destes processos.

\footnotetext{
${ }^{4}$ Neste ensaio não me refiro à pesquisa artística que pode ser desenvolvida por profissionais fora do âmbito das instituições de ensino superior ou de centros de pesquisa especializados.
} 
Por esta perspectiva, nem toda criação artística implica numa pesquisa tal e como estamos delimitando o termo. Para isto deveria cumprir certos requisitos. Henk Borgdorff assinala os seguintes:

\begin{abstract}
A prática artística pode ser qualificada como pesquisa caso o seu propósito seja aumentar nosso conhecimento e compreensão, levando adiante uma pesquisa original em e através de objetos artísticos e processos criativos. A pesquisa em arte inicia fazendo perguntas pertinentes ao contexto da pesquisa e ao mundo da arte. Os pesquisadores adotam métodos experimentais e hermenêuticos que mostram e articulam o conhecimento tácito que está localizado e encarnado em obras e processos artísticos específicos. Os processos e os resultados da investigação são documentados e divulgados de maneira apropriada para a comunidade acadêmica e o público mais amplo (Borgdorff 2012, p. 53).
\end{abstract}

Esta definição requer um exame mais detalhado. Por um lado, observamos que um dos seus requisitos é o desejo expresso de produzir um conhecimento novo e que esse conhecimento possa colaborar para satisfazer as necessidades próprias do meio artístico. Da mesma maneira, como em qualquer tipo de pesquisa, seus processos e resultados deverão estar documentados e divulgados no contexto da comunidade interessada. No entanto, há dois elementos nesta aproximação de Borgdorff que podem resultar mais problemáticos. Esta modalidade de pesquisa está fortemente vinculada a alguma produção artística como resultado de processos criativos. Deste modo, a pesquisa se realiza "em e através" dos mesmos objetos e processos que formam parte dos produtos da pesquisa. São, ao mesmo tempo, o meio e o resultado da investigação. Da mesma maneira, os métodos de pesquisa tendem a revelar, tornar explícitos ou pelo menos organizar, os conhecimentos tácitos encarnados nestas obras e processos. Estes elementos outorgam complexidade ao processo e ao resultado da pesquisa artística.

\title{
3. O papel cognoscitivo da pesquisa artística na interpretação musical
}

Florian Dombois, sugere que, tendo a ciência explicado o mundo de maneira bem sucedida, mas não exaustiva, requer-se agora uma alternativa de conhecimento que focalize os aspectos ignorados ou negados pela própria ciência (citado em Borgdorff, 2013, p. 158). Uma dessas alternativas é a pesquisa artística. Entretanto, o tipo de pesquisa desenvolvida no terreno musical não se caracteriza por retomar perguntas, inquietudes e problemas atuais, da maneira 
como o fazem outras áreas do conhecimento. Ao contrário de outras artes, (a música) não costuma se preocupar com as comunidades virtuais, a identidade, a imigração, o terrorismo, a pobreza, o câncer, a crise ocidental, os fundamentalistas religiosos, etc. Se olharmos as teses e trabalhos finais do primeiro, segundo e terceiro ciclo, podemos observar que a grande maioria dos projetos se ocupam com objetivos mais modestos e domésticos: problematizar e dar resposta a inquietudes próprias do campo de ação profissional musical. ${ }^{5}$

Vamos examinar qual é o objeto de estudo formal das pesquisas em interpretação musical; qual a natureza do conhecimento que elas produzem e qual sua maneira de construção, comunicação e veiculação. ${ }^{6} \mathrm{Na}$ prática, estas três dimensões estão intimamente vinculadas entre si e não é possível distinguilas tão claramente. Faremos esta distinção por motivos expositivos.

\section{A dimensão ontológica: os objetos de estudo}

A partir da análise de vários casos apresentados recentemente (López-Cano e San Cristóbal, 2014), observamos que a pesquisa em interpretação musical se concentra em problemas vinculados a: 1. Práticas interpretativas; 2. Processos criativos; 3. Exercício profissional e 4. Práticas pessoais.

\subsection{Práticas interpretativas}

A pesquisa na práxis interpretativa pode incluir a análise de técnicas instrumentais e de estilos de interpretação de determinadas músicas, épocas e lugares. Está baseada em tratados escritos, testemunhos de intérpretes famosos ou na análise de gravações. Geralmente se fazem análises comparativas entre diferentes interpretações de uma mesma obra, a caracterização do estilo interpretativo de um músico em especial ou suas transformações ao longo do tempo, junto ao estudo das características de diferentes elementos da performance, tais como, aspectos cênicos, gestuais e de interação com outros músicos e com os espectadores (López-Cano e San Cristóbal, 2014, p. 229-231). Estas áreas já estavam sendo atendidas pela musicologia com ênfase na

\footnotetext{
${ }^{5}$ Borgdorff as chama de questões intradisciplinares (Borgdorff 2013, 149).

${ }^{6}$ A primeira questão é chamada por Borgdorff como a pergunta ontológica (Borgdorff 2012, p. 4546), a segunda pergunta epistemológica (Borgdorff 2012, p 47,48). Da terceira ele não se ocupa.
} 
performance (Juslin, 2001; Clarke, 2004; Bowen, 2008; Cook, 2010; LeechWilkinson, 2010). No entanto, ao contrário desta, a pesquisa artística se interessa nestes campos não para descreve-los ou analisa-los, senão para informar criticamente a própria interpretação do pesquisador. É conhecimento orientado para a ação.

Aos jazzistas, por exemplo, interessa-Ihes apropriar-se de alguma característica interpretativa específica de outros estilos ou músicos. Os estudantes de música antiga costumam complementar a leitura de velhos tratados com entrevistas a intérpretes atuais de prestígio e, em várias ocasiões, apontam inconsistências entre a informação histórica e a prática real. Costumam priorizar a segunda, pois seus interesses de conhecimento não estão orientados para a história, senão ao seu exercício profissional atual. Quando a informação histórica é escassa, não duvidam em supri-la com experimentação e proposição de práticas hipotéticas, embora artisticamente eficazes. ${ }^{7}$ Além da reconstrução de práticas interpretativas históricas, existe a invenção de novas técnicas ou estilos.

Alguns trabalhos problematizam, refletem e experimentam aspectos da práxis interpretativa que não tem sido abordados pelas disciplinas acadêmicas ou que introduzem um ponto de vista e interesse de conhecimento diferente aos da musicologia. ${ }^{8}$ Uma característica relevante é o papel da experimentação do próprio instrumento musical como lugar de problematização, reflexão, teste e comunicação da pesquisa. Em alguns casos, a própria interpretação musical é analisada a posteriori, como se os músicos-pesquisadores fossem analistas independentes do intérprete (López-Cano e San Cristóbal, 2014, p. 196).

\subsection{Processo criativo}

Coloca o foco de atenção no processo de construção da interpretação musical mais do que nos resultados. Registra e documenta o processo interpretativo; oferece relatórios descritivos ou analíticos sobre a eleição dos critérios de

\footnotetext{
7 Ver o trabalho de reconstrução da prática do baixo continuo para a viola da gamba e o violoncelo de R. Smith (2009).

8 Ver, por exemplo, o texto de Jan (Schacher, 2013) sobre o impacto do trabalho com tecnologia e corporeidade; a reflexão sobre a colaboração entre instrumentista e compositores de Stefan Östersjö, (López-Cano e San Cristóbal, 2014, p. 240) ou as conceptualizações sobre os elementos da performance em diversas artes cênicas no trabalho de Pedro González (López-Cano e San Cristóbal, 2014, p. 114, 117, 171, 176, 179, 181).
} 
interpretação, as razões pelas quais se escolheu tal andamento ou frase, a maneira como surgiram as ideias, a inspiração ou os materiais. Adota a forma de memória, texto escrito ou documentário audiovisual tipo Making off. Neste âmbito, se realizam análises musicais das obras interpretadas utilizando metodologias distintas da análise formal. Aqui não se pretende explicar as características formais ou funcionais das obras, senão fundamentar ou gerar ideias para a interpretação. Não costuma conter teorias muito profundas e sua argumentação é intermitente, sem a coerência da análise teórica. Mais uma vez trata-se de um conhecimento orientando a ação. ${ }^{9}$ Exemplos de processos criativos:

The Virtual Haydn de Tom Beguin, Naxos, BLU RAY AUDIO (making off) e palestra "A new experience in performance".

\subsection{Exercício profissional}

Uma grande quantidade de trabalhos reflete, analisa, critica e propõe alternativas ao modo de representação e difusão da música; como e onde se interpreta, os rituais do concerto clássico, os limites dos formatos habituais de difusão, a renovação do desenvolvimento performático, as alternativas de radiodifusão e gravação, etc. Com frequência, estes trabalhos, propõem modelos de concertos inovadores; trabalham incansavelmente para conhecer e melhorar o impacto dos aspectos cênicos ou gestuais, inclusive desenvolvendo performances audiovisuais (San Cristóbal e López-Cano, 2013). Seu trabalho tende a transformar, melhorar, analisar ou criticar a prática musical dentro da comunidade profissional dos músicos atuais.

Suas intenções de conhecimento também estão dirigidas para a prática. Elas se interessam pelo melhoramento da atividade profissional do músico, a criação de novos público e novos repertórios; a intervenção no repertório canônico, realização de arranjos e composições, reconstrução de obras inconclusas ou

\footnotetext{
9 Para bons exemplos deste tipo de pesquisas ver Around a Rondo de Stephen Emmerson (LópezCano e San Cristóbal, 2014, p. 222-223); De la repetition au concert de Remy Campos (López Cano, 2013) ou La pronuntiatio musicale une interprétation rhétorique au service de Händel, Montéclair, C. P. E. Bach et Telemann de Rafael (Palacios Quiroz, 2012).
} 
perdidas; até mesmo a invenção de repertórios utópicos; ${ }^{10}$ geração de improvisações, encenações, interação com aspectos visuais; aperfeiçoamento da performance corporal; novos modelos de gestão, etc. Caracterizam-se metodologicamente pela promoção de situações de experimentação e avaliação de resultados. ${ }^{11}$ Exemplos de prática artística:

Proyecto Delta: interrelación entre intérprete, obra y público en la música. Proyecto final de carrera (ESMuC 2013) de Juan José Faccio.

Análisis interpretativo de la voz y del gesto en la práctica de la percusión. Proyecto final de máster (ESMuC 2014) de Rubén Martinez Orio.

un bruit de création... (2013). Metamorphosis on Beethoven's keyboard exercises from the Kafka Miscellany and four unpublished. Tropos Ensemble: Luca Chiantore \& David Ortolà.

\subsection{Técnicas personalizadas}

Muitos trabalhos relatam um processo individual destinado a desenvolver uma técnica ou metodologia no âmbito da interpretação, técnica instrumental, higiene postural e experiência cênica. Eles apresentam um forte componente de avaliação que qualifica os efeitos da técnica praticada. Muitas vezes os pesquisadores realizam adaptações pessoais dos métodos usados e realizam consultas com especialistas inclusive fora do âmbito musical, como treinadores nas áreas esportivas. Com isto, colocam em prática diversos métodos para desenvolver alguma habilidade técnica do instrumento, estimular a memória, concentração ou relaxamento, combater a ansiedade cênica, o estresse, as doenças corporais ou potencializar o bem estar na experiência da performance (estados de flow), etc. ${ }^{12}$

Geralmente, estes trabalhos aproveitam conhecimentos bem estabelecidos em outros âmbitos. Não costumam realizar grandes contribuições- entretanto, sua implementação no mundo musical pode ser inovadora. Regularmente realizam uma autoetnografia onde registram sua evolução e rendimento (López-Cano e San Cristóbal 2014, p. 135-167). Estes estudos particulares servem muito bem

\footnotetext{
10 Ver o trabalho de mestrado An interpretation of the hypothetical concertante style of Schubert: Konzertstück for Piano and Orchestra, adapted from Lebensstürme D. 947 de Óscar Caravaca González (López-Cano e San Cristóbal 2014, p. 223).

11 Outros exemplos de experimentação em pesquisa artística em López-Cano e San Cristóbal, 2014, p. 107, 173-183, 223.

12 Ver o trabalho Flow: en busca del duende de Reina Navarro (López-Cano e San Cristóbal 2014, 172).
} 
como modelo para novas experiências similares. A prazo médio, a revisão crítica de vários trabalhos pode dar lugar a novos métodos desenvolvidos exclusivamente para o meio musical.

\section{Dimensão epistêmica: O conhecimento produzido}

$\mathrm{Na}$ maioria dos espaços, onde se realiza pesquisa artística em interpretação musical, se espera - como resultado, tanto a geração de um objeto artístico (característica diferenciadora de outros modelos de pesquisa), como a construção de um discurso que, de maneira regular, adquire a forma de um relatório, memória ou trabalho escrito que é arguido durante uma apresentação especial. ${ }^{13}$ Da mesma maneira que os objetos de estudo oscilam entre processos e produtos do trabalho criativo, o conhecimento resultante também parece ser distribuído em vários lugares, adota diversas funções, é comunicado, apreendido e valorado por distintos meios.

O discurso escrito pode incluir a documentação ou registro do processo de criação, as perguntas iniciais da pesquisa, ${ }^{14}$ argumentações, justificações, reflexões, interpretações, inferências, reformulação e construção de novas perguntas de pesquisa, etc. Na sua totalidade ou por momentos, pode adotar as características de um escrito científico ou acadêmico habitual. Está fundamentado em construções conceituais e abstratas que bem podem ser tomadas das teorias contemporâneas ou clássicas legitimadas pela academia, ou podem propor termos e conceitos próprios. Ocasionalmente, pode se apresentar como um relatório técnico ou, inclusive, ter alguma dimensão estética em si mesma (López-Cano e San Cristóbal 2014, p. 185-205). Este discurso pode teorizar sobre alguns aspectos do objeto artístico resultante, mas também pode funcionar como um elemento informador e formador deste. No primeiro caso, o discurso, em relação ao objeto artístico (a interpretação musical), se colocaria no nível epistêmico das construções teóricas sobre o objeto de estudo, com

\footnotetext{
${ }^{13} \mathrm{Em}$ alguns centros de ensino de arte dramática, este trabalho escrito pode ser substituído por registros audiovisuais. Na música ainda não existe essa opção. A norma geral é que a defesa adquira a forma de comunicação ou apresentação oral, mas em alguns lugares se realiza na maneira de masterclass, workshop ou palestra-concerto.

14 A "pergunta inicial de pesquisa" é um conceito técnico que designa a ou as perguntas de pesquisa principais, as quais o trabalho pretende responder. Não se refere necessariamente às primeiras preocupações que aparecem cronologicamente no início do processo. Ver a seção 6 Problema ou pergunta de investigação (López-Cano e San Cristóbal, 2014, p. 69-82).
} 
entidade, lógica e coerência particulares. No segundo caso, colocar-se-ia no nível epistêmico do próprio objeto de estudo. É comum que, epistemologicamente, o discurso oscile de maneira intermitente entre estes dois níveis.

O objeto artístico resultante também forma parte do tecido de conhecimento produzido. Por um lado, é a resposta principal (ou pelo menos uma delas) para as perguntas de pesquisa iniciais. Também é o espaço onde as reflexões e ações de pesquisa são validadas ou negadas; pode-se considerar como uma instância que gera conhecimento através da experiência estética em suas múltiplas interpretações. O objeto possui um conhecimento tácito. Como afirmam os teóricos do desenho, tem uma "densidade sensorial com um elevado conteúdo informativo de conhecimento incorporado que remete a lugares que a ciência, com frequência, tem dificuldades de capturar e descrever" (Brix, 2008). Encarna uma inteligência intrínseca que se faz acessível somente através da experiência estética (Schacher, 2013). É um conhecimento não verbal, com uma coerência particular, corporal, cujo aspecto emocional, analógico e intuitivo desenvolve um papel fundamental. Mas, como toda proposta artística, está aberta a múltiplas interpretações e também apresenta um caráter volátil e imprevisível.

Há um terceiro tipo de produção de conhecimento que pode ser difícil de comunicação, seja no âmbito do discurso, seja no próprio espaço estético: o conjunto de ações corporais, habilidades e experiências motoras e cinéticas desenvolvidas, descobertas, aprendidas e executadas como resultado da pesquisa artística. Muitas práticas artísticas, tais como a dança, o teatro e a interpretação musical, exigem o desenvolvimento destas habilidades que em certas ocasiões são impossíveis de serem descritas verbalmente. Apesar de ocasionalmente ser o suporte das qualidades estéticas do objeto artístico, como acontece nos registros fonográficos, não são percebidas diretamente e podem não estar presentes na representação dos resultados da pesquisa. Algumas destas ações motoras têm incidência direta na produção do som musical (movimentos de efeito), mas outras, possuem funções que vão desde o acompanhamento à execução, com evidente caráter expressivo e artístico em sं mesmos (López-Cano 2009; Godoy e Leman, 2010).

Existem também uma série de "ações mentais" resistentes à verbalização que na maioria das vezes estão intimamente vinculadas à atividade motora produtora da interpretação musical e que, em ocasiões, constitui sua única via de expressão. 
Refiro-me às análises não formalizadas ou racionalizadas, ou à compreensão da obra baseada na intuição e nas experiências de escuta e interpretação prévias. Também me refiro a certas decisões interpretativas tomadas no preciso momento da leitura musical e da resolução de problemas técnicos específicos, não refletidos, pensados, conscientes ou verbalizados. Estes, por vezes, têm um componente pessoal altíssimo e ocupam um lugar fundamental na proposta de interpretação de uma obra específica.

Como podemos observar, o conhecimento resultante da pesquisa artística em interpretação musical oscila entre a techné e a episteme gregas e são distribuídas entre o espaço (escrito ou oral), o objeto ou processo artístico produzido e a performance motora que a prepara e executa.

Esta distribuição gnosiológica pode ser desigual em cada caso e pode ser que a carga de conhecimento se concentre ou desapareça em algum elemento mais do que em outro.

\section{Conhecimento conceitual versus conhecimento não conceitual}

Antes de analisar este aspecto particular do conhecimento é necessário esclarecer alguns termos. Frequentemente se diz que as atividades não científicas, como a arte, oferecem experiências cognoscitivas de natureza não conceitual, pré-linguísticas, pré-reflexivas, implícitas ou tácitas que resistem a serem expressas por meios verbais. Estas experiências contrastam com as experiências cognoscitivas conceituais, reflexivas, verbais e explícitas presentes na ciência. Eu acredito que essas oposições binárias são insuficientes, pois omitem alguns elementos indispensáveis para uma análise mais aprofundada dos diversos modos de conhecimento. Os conceitos são "os constituintes dos pensamentos" e têm um papel fundamental em "processos psicológicos como a categorização, as inferências, a memória, o aprendizado e a tomada de decisões" (Margolis e Laurence, 2014). Normalmente, quando o tema do debate é o pensamento conceitual, consideram-se unicamente os conceitos lexicais: aqueles que correspondem aos "itens lexicais das línguas naturais", tais como "pássaro", "solteiro", etc. É bastante "comum pensar que as palavras nas línguas naturais têm seus significados derivados dos conceitos usados para expressá-los" (Laurence e Margolis, 1999). Entretanto, os processos da elaboração de 
conceitos consideram muitos outros mecanismos e o significado de alguns elementos, incluindo as palavras, podem derivar das ações e usos específicos mais que da sua etimologia.

Segundo a definição anterior, o pensamento conceitual se relaciona com os processos de categorização e inferência, mas estes podem acontecer de diversas maneiras, inclusive em situações não intermediadas necessariamente pela conceptualização lexical a expressão verbal. São célebres, por exemplo, os estudos sobre a categorização da cor de Eleanor Rosch, nos quais ela demonstrou que, apesar de os Dani da Nova Guiné possuírem somente duas palavras para designar todas as cores, eram capazes de reconhecer sistematicamente, através de processos de categorização por protótipos, variantes de cores para as quais não existem termos verbais (Heider, 1972; Heider e Olivier, 1972; Varela; Thompson e Rosch, 1992, p. 197-201). Os melômanos sem formação em teoria musical são capazes de categorizar e reconhecer diferentes tipos de cadências, mesmo sem conhecer os seus nomes técnicos. Os músicos podem categorizar padrões rítmicos, reconhecê-los e extrai-los do fluxo musical sem a necessidade de ter um nome específico para cada um deles (Desain e Honing, 2003). Eles podem traduzi-los em notação musical depois de analisa-los, mas isto é uma tarefa cognitiva diferente. Seu reconhecimento não depende dela. Um intérprete organiza categorias de gestos, tempos, graus de intensidade e tipos, ou amplidão de movimentos. A fronteira entre categorias de processos não verbais, como por exemplo, cor e gesto, pode ser difusa e os critérios de identificação, bastante instáveis. Mas, isso também é categorizar e elaborar esquemas mentais, roteiros ou tipos de conhecimento (López-Cano, 2004, p. 422-480). Faz parte do pensamento conceitual não lexical e da cognição.

A inferência é um procedimento lógico no qual partimos de premissas estabelecidas (percebidas ou conhecidas anteriormente) para extrair uma conclusão por meio de operações lógicas que atuam por indução, dedução ou abdução. Entretanto, existem processos de geração de conclusões a partir de um conhecimento prévio do mundo, que se baseiam em conjeturas intuitivas, padrões analógicos ou processos metafóricos. São bem conhecidas as teorias de George Lakoff e Mark Johnson, segundo as quais muitos fenômenos complexos e abstratos são conceituados por meio de projeções metafóricas de esquemas 
mentais corporizados (esquemas imagem) formados por experiências motoras primárias caracterizadas por serem não propositivas, pré-verbais e pré-racionais (Johnson, 1987; Lakoff e Johnson 1998; Lakoff, 1987; Johnson, 2007). Desta maneira podemos conceituar fenômenos tão abstratos como o "tempo", como se este fosse um objeto manipulável que "se perde", "se ganha", "se rouba", "se dá de presente", "se tira", etc. As teorias dos esquemas de imagem e sua projeção metafórica têm sido empregadas na explicação que fazemos da nossa experiência musical. Fenômenos habituais onde a partir da escuta de um evento musical $X$ inferimos o evento seguinte $Y$, gerando uma forte expectativa, se apoiam comumente em alguns destes esquemas (López-Cano, 2003; Peñalba, 2005).

Por outro lado, é bem conhecido que as inferências realizadas na maioria das ciências humanas, como a filosofia, história, filologia e as ciências sociais, como a antropologia, não se fundamentam em operações lógicas estáveis, bem definidas e suscetíveis de serem reconstruídas logicamente, passo-a-passo, por meio de operações lógicas clássicas. Estas áreas agem por interpretações baseadas na inteligência emocional e subjetiva, por meio da empatia e dos princípios hermenêuticos que orientam a interpretação. Entre estes, podemos mencionar: o círculo hermenêutico, os critérios de autoridade e a tradição, a economia interpretativa (a interpretação mais simples é a melhor), a consistência do mesmo princípio de interpretação aplicados em outros casos, a força persuasiva do discurso com o qual se argumenta, etc. (Mardones, 1991). Muitos destes critérios são considerados pela lógica clássica como "falácias", mas as ciências duras também recorrem a eles, ocasionalmente.

Deste modo, observamos que oposições binárias como conceitual/não conceitual, carecem de sentido e ocultam uma grande variedade de modos de pensamento e de apropriação do conhecimento. É necessário distinguir entre conceptualização lexical e outros tipos de conceptualização, para aceitar que a inferência não se esgota em processos lógicos aristotélicos. ${ }^{15}$ Com isto em mente, analisaremos as três grandes áreas gnosiológicas que caracterizam a produção de conhecimento na investigação artística em interpretação musical: 1) os conhecimentos e saberes formais, racionais e lógicos comuns a todas as áreas de pesquisa acadêmica-universitária; 2) os conhecimentos e saberes processuais vinculados

15 Ou através da lógica conídica como foi chamada por Cornelius (Castoriadis, 1999, p. 273). 
à prática e 3) os conhecimentos e saberes intuitivos, sensíveis, tácitos e não verbais. Estas áreas se manifestam em três produtos da pesquisa artística: a) o discurso escrito ou oral; b) as ações desenvolvidas para gerar a interpretação e c) o objeto artístico, a interpretação, performance ou gravação. Cada área gnosiológica estabelece diversas relações com cada produto. Mais uma vez, estas áreas estão vinculadas intimamente entre si. Na realidade se entrelaçam e se fundem de múltiplas maneiras. A seguir as analisaremos separadamente por motivos puramente didáticos.

\section{Conhecimento formal}

Trata-se de conhecimento proposicional, expressado por meios verbais e obtido por meio da reflexão, da análise e da interpretação. ${ }^{16}$ É um conhecimento racional e lógico, mas, como mencionado anteriormente, também se baseia em inferências não inteiramente lógicas, fundamentadas na interpretação, empatia, analogia, metáfora e hermenêutica. Seu traço comum revela que é discursivo e prioriza a conceptualização lexical. Este tipo de conhecimento se veicula fundamentalmente através do discurso. Com frequência adota o formato de conhecimento acadêmico. Emprega a terminologia e conceitos habituais da academia ou, propõe outros originais. Quando a pesquisa artística aborda problemas comuns com a musicologia ou outras disciplinas acadêmicas, fica mais fácil a produção deste tipo de conhecimento. Em alguns casos, as conceptualizações proposicionais podem ser da mesma profundidade que as de um teórico. Em outros, seu interesse jaz a partir de outro lugar, um interesse de conhecimento distinto. Em alguns casos, a reflexão fica limitada. Isto pode acontecer devido à formação e especialização do autor ou dos seus interesses de conhecimento.

O pensamento proposicional pode funcionar como conhecimento baseado na prática: Os trabalhos sobre interpretação musical costumam refletir criticamente sobre a própria prática interpretativa. Esta fornece o material para pensar intelectualmente. Também pode ser conhecimento dirigido à prática: a conceptualização não visa uma compreensão teórica do fenômeno estudado, mas sim, a geração de recursos para a prática ou para as ações. Aqui as

${ }^{16}$ Borgdorff a chama perspectiva interpretativa (Borgdorff, 2012, p. 38). 
conceptualizações lexicais ou inferências são limitadas e truncadas, pois apontam para ações específicas e co-determinadas por estas mesmas ações, fazendo com que a força argumentativa recaia sobre a sua eficácia. Aquilo que foi verbalizado forma só uma parte do conhecimento o qual se complementa através dos saberes procedimentais manifestados nas ações. O discurso é uma predisposição à ação.

A verbalização do conhecimento embebido na prática é mais complexa. Quando as ações não podem ser determinadas pelo pensamento conceitual léxico, quando é muito difícil individualizá-las, descrevê-las, rotulá-las com um nome e propriedades específicas que as distinguem de outras, podem-se adotar outras estratégias diversas. Entre elas, a especificação de intenções ou metas da ação: Que tipo de som, emotividade musical ou experiência corpórea deseja ser produzida pela ação? Podem ser descritos também, sem serem analisados posteriormente, os sentimentos e pensamentos vinculados às ações ou às rotinas motoras. Em alguns casos é possível formalizar detalhadamente um procedimento experimental para várias ações e se propor a escolher dentre elas a melhor solução para um problema técnico ou musical. Nestes casos pode-se descrever muito bem os detalhes da experimentação, dos critérios de avaliação e o resultado do mesmo. Também pode-se utilizar algumas qualidades da ação, como as dificuldades ou possibilidades que oferece. Como podemos observar, nestes casos, o discurso tangencia o conhecimento sem verbalizá-lo diretamente. Contudo, é possível representar ou empregar o conhecimento proposicional nas ações artísticas. Existem trabalhos nos quais os discursos musicológicos, críticos, estéticos ou históricos, são relidos para extrair deles indicações de interpretação, para inferir práticas e ações interpretativas, colocando de lado outro tipo de valoração ou informação. ${ }^{17}$ Finalmente, o conhecimento proposicional também tem severas limitações de expressão em relação ao conhecimento tácito embebido no objeto artístico. De forma regular, a pesquisa artística em interpretação musical manifesta-se na construção de uma poética explícita pessoal, onde o autor põe em discurso alguma parte desse conhecimento estético quando expressa o que pretende suscitar com seu projeto criativo, ou

17 Ver The reception of 19th century opera and implications for today's performers de Massimo Zicari (López-Cano e San Cristóbal, 2014, p. 88-89) ou Viajeros románticos en el flamenco de Isabelle Laudenbach (López-Cano e San Cristóbal, 2014, p. 92). 
bem, analisa o que este despertou em seus espectadores através da interpretação hermenêutica, entrevistas, pesquisas ou grupos focais.

\section{Conhecimento vinculado à prática}

Trata-se de um conhecimento processual-funcional; é o "saber fazer" ou o "saber como". É o conhecimento prático baseado na experiência e manifestado na prática. Portanto, é o conhecimento em ação. ${ }^{18}$ Baseia-se na reflexão por meio da ação ou na prática quando esta é o objeto-espaço de reflexão, dando lugar aos diferentes saberes, inclusive os proposicionais; conhecimento dirigido à prática, quando as construções cognoscitivas não são autossuficientes e precisam se complementar com algum tipo de ação; ou conhecimento embebido na prática, quando está integrado por ações com pouca ou nenhuma possibilidade de ser representado por outro meio. A interpretação musical se encarna em ações físicas macro e micro-gestuais desenvolvidas pelo intérprete para resolver tecnicamente a execução de uma obra e alcançar a interpretação desejada. Mas também, em certas atividades "mentais" que não podem ser explicadas pela reflexão organizada nem expressadas inteiramente através de palavras, tais como certas decisões interpretativas, análises ou compreensões das obras interpretadas que procedem de maneira intuitiva e pouco organizada desde o ponto de vista lógico. ${ }^{19}$

Este desenvolvimento da performance está vinculado à relação, consciente ou não, do músico com seu próprio corpo, através de esquemas de imagens corporais, alguma imagem sonora do resultado que se deseja obter ou também, ao estado expressivo-emocional que deseja comunicar. De maneira singular, oferece resistências à racionalização e é evasivo à conceptualização lexical, portanto, devido a isto, na prática docente, costumam ser utilizados métodos ostensivos para comunicá-1020: o professor ou músico mais experiente demonstra ao estudante ou músico menos experiente a maneira como deve fazer e este

\footnotetext{
18 Similar àquilo que Borgdorff chama perspectiva performativa (Borgdorff, 2012, p. 38) embora ele Ihe atribua alguns elementos distintos.

19 Sobre os componentes e características do conhecimento intuitivo, ver (Hogarth 2002). É indispensável uma análise mais detalhada sobre qual é o conhecimento desenvolvido na pesquisa artística.

20 Lembre-se que a ostentação é um modo de pensamento que comunica um saber demonstrando um exemplo do mesmo. À pergunta, o que é um lápis? respondemos mostrando um exemplar sem utilizar definições técnicas.
} 
aprende através da imitação. Com frequência, se verbalizam partes das rotinas motoras, a intenção mental que as detona, as sensações ou propriocepções que a acompanham, etc. A verbalização truncada costuma estar acompanhada de ações motoras sobre o instrumento ou de gestos dramatizados tentando indicar o que se tenta alcançar.

As "inferências" tornam-se a forma de produção de conhecimento motor de maneira geral através da via ensaio-erro. Quando os resultados esperados são atingidos, interioriza-se o gesto adequado por meio da repetição. ${ }^{21}$ Existem, entretanto, processos de categorização corporal. Por exemplo, para realizar uma tarefa repetitiva, tal como um ataque especifico num instrumento, pode-se distinguir entre diferentes tipos de movimentos similares que podem ser organizados em escalas ou graus, segundo a intensidade ou direção do gesto, as qualidades do resultado sonoro ou pela expressividade obtida. Normalmente, os elementos destas escalas não estão perfeitamente definidos nem as suas fronteiras são claras. Esta categorização pode ser efêmera, quer dizer, funciona no momento em que é criada e pode não ser representada e estabelecida de maneira fixa e permanente. Regularmente, as inferências lógicas e as categorizações são incompletas a nível mental e somente se completam através da própria ação: são duas peças do mesmo quebra-cabeça.

De que maneira se relaciona o conhecimento processual com os elementos discursivos que produzem a pesquisa artística? Como foi observado, uma parte do mundo das ações pode ser representada por meio de conhecimento proposicional (seria melhor: conhecimento proposicional baseado na ação). Em certas ocasiões, a mesma prática musical matiza, contradiz ou testa o conhecimento proposicional gerado em outra etapa da pesquisa. Em outros casos, as conceptualizações léxicas são limitadas e só adquirirem sentido quando se complementam com ações determinadas (conhecimento proposicional dirigido à ação). Criam-se deste modo vínculos indiciais entre as construções verbais e as ações. Em muitos casos, as construções verbais de um texto ou apresentação oral, vêm acompanhadas de imagens, gravações audiovisuais ou execuções ao

\footnotetext{
${ }^{21} \mathrm{Na}$ metodologia da pesquisa artística se promove a formalização destes processos através da definição verbal dos objetivos ou resultados esperados da ação, seu registro e análise e a comparação por diversos meios, de várias opções de ações (López-Cano e San Cristóbal, 2014, p. 123-183).
} 
vivo das ações referidas. Pode-se inclusive representar por meios audiovisuais com voz em off ou legendas.

Uma estratégia frequente procura descrever as ações gerais no formato de relatório (López-Cano e San Cristóbal, 2014, p. 193-194). Esta forma de discurso pode não estabelecer conceitos para cada uma das ações importantes, simplesmente descreve a grosso modo o que foi feito e os resultados pessoais atingidos. O desenvolvimento obtido pode ser comunicado através de gráficos ou estatísticas elaboradas com os dados recolhidos sistematicamente ao longo do processo. Há trabalhos nos quais as construções verbais se detêm em explanar exercícios específicos e o leitor é convidado a repetir estes movimentos para experimentar certas sensações corporais ou musicais que são as que verdadeiramente comunicam o conhecimento exposto. Em certas ocasiões se emprega a estratégia de escrita conhecida como texto confessional onde se expressa o mundo de significado pessoal e intransferível que emerge da experiência de interpretação sem ser analisado ou interpretado com profundidade (López-Cano e San Cristóbal, 2014, p. 203). Há outros elementos que ajudam na elaboração do discurso sobre este conhecimento processual. Trata-se de discursivizações não verbais como as esquematizações de formas e estruturas de obras ou indicações de interpretação nas partituras. Costumam ser pouco explícitas, mas com a capacidade suficiente para indicar ações e relembrar intenções interpretativas. Nestes casos solicita-se ao autor ampliar os seus gráficos, enriquecê-los, aprofundá-los, acrescentar a informação revelada neles e aumentar sua complexidade. A partir deles pode-se criar um mapa de suas intenções interpretativas, conceitualizar os diferentes níveis e tipos de dinâmica, articulação ou frase que vai ser utilizada e agrupada novamente em categorias. Também pode ser elaborado um vídeo no qual as imagens de suas anotações e esquemas se alternam ou sobrepõem à gravação de ações durante a performance. Pode também filmar a si mesmo, realizando as ações a partir de diferentes ângulos e comparando-as com as suas anotações na partitura.

Em relação às compreensões ou análises intuitivas, subjetivas e personalizados das obras, podem ser colocadas em discurso verbal e não verbal através da reflexão ou descrição de alguns dos elementos tomados em consideração para esta compreensão, tais como, textos críticos, poemas, outras obras musicais e não musicais nas quais podem ser detectados vínculos intertextuais com as 
obras analisadas, etc. ${ }^{22}$ No texto não aparece explicitamente a compreensão, mas sim as fontes e algumas das reflexões verbalizadas da mesma.

\section{Conhecimento vinculado ao sensível e ao intuitivo}

A pesquisa artística produz uma grande quantidade de conhecimento sensível, implícito e tácito, resistente à racionalização, portador de uma coerência distinta, emocional e intuitiva. Encarna-se no objeto artístico resultante ${ }^{23}$ e é possível de ser acessado, através da sua análise ou através da experiência estética. ${ }^{24}$ Como foi observado, o conhecimento processual pode dar conta de algumas das intenções ou alguns dos resultados da experiência estética proposta. ${ }^{25}$ No entanto, existem muitos elementos destas que são irredutíveis à linguagem. Sua natureza não é conceitual-lexical, embora possa se expressar através da tradução intersemiótica, através de metáforas visuais, gestuais ou narrativas, gritos e interjeições, guturalizações, etc., que permitem transmitir mais as intenções daquilo que se deseja expressar ou dizer do que os conteúdos ou referentes exatos.

Trata-se de um conhecimento empático com forte raiz nas crenças. Sua conceptualização costuma ter referência no impacto emotivo-corporal de uma experiência com frequência intuitiva ou sensível. É comum a projeção metafórica de esquemas imagem corporais, cinéticos, que nos permitem descrever a música como um corpo em movimento. As "inferências", por vezes, funcionam através de redes intertextuais que evocam outras obras de arte para conferir sentido à obra de arte em questão. Este conhecimento costuma acontecer somente em presença do próprio objeto artístico, portanto, mais que inferenciais, seus

22 É o caso de El violoncello en imágenes de Marta Requena (López-Cano e San Cristóbal, 2014, p. 214).

23 Como observamos, também o conhecimento processual pode produzir este tipo de conhecimento. Precisamos lembrar que algumas performances não pretendem ser o lugar de fixação do conhecimento, senão espaços para a experimentação donde se produz o conhecimento. Ver o projeto Tangencias (Tendências) de Pedro González (López-Cano e San Cristóbal, 2014, p. 114, 117, 171, 176, 179, 181). Tangencias (ESMuC 2014) de Pedro González. Disponível em: https://youtu.be/I6dUjl1ths4. Acesso em: 28 maio 2015.

24 Frequentemente a análise dá lugar ao conhecimento proposicional. Se a análise é mais imediata e intuitiva poderia gerar conhecimento processual. A análise também produz conhecimento implícito em outros níveis da experiência analítica.

25 Em relação ao conhecimento discursivo ou às ações, os objetos artísticos podem exemplificar, ampliar, complementar, matizar ou inclusive negar (deliberada ou involuntariamente), os conhecimentos verbais ou práticos. 
possíveis conteúdos não verbais, emotivos e corporais são de natureza intencional ao objeto. Essa intencionalidade permite conectar o objeto com os propósitos da pesquisa, pois, deve-se lembrar que as obras de arte, junto com as teorias científicas, pertencem ao terceiro mundo epistêmico proposto por Karl Popper (1974, p. 106): podem tornar-se independentes das intenções originais dos seus autores e gerar interpretações e significados múltiplos. Devido a isto, aqui nos interessam os objetos artísticos não como obras autônomas, senão exclusivamente em relação ao projeto de pesquisa vinculado aos discursos e ações produzidos durante o processo. A experiência estética pode ser uma experiência cognoscitiva, mas nem toda ela pode ter relação com a argumentação da pesquisa.

Como se poderia elaborar um discurso acerca do conhecimento contido ou desenvolvido pelo objeto artístico? Existem elementos em torno da performance musical que são facilmente verbalizáveis, tais como os contextos históricos e seus antecedentes, seus predecessores, tradições onde se insere, história, teoria, etc. Uma estratégia muito frequente é analisar a posteriori a interpretação musical. Pode-se falar também das intenções da proposta interpretativa: que tipo de som se deseja produzir, quais emoções ou impressões se tenta despertar no público. Um elemento de formalização do conhecimento desenvolvido pela interpretação consiste na avaliação elaborada por uma ou várias pessoas através de entrevistas, diálogos, pesquisas ou grupos focais. ${ }^{26}$ É muito frequente encontrar reflexões sobre o elemento que se integra e que será usado na performance ou alguma informação histórica como inspiração para uma performance. Em ocasiões se utilizam entrevistas e diálogos com outros artistas sobre temas de interesse para eles, colocados, dirigidos e comunicados através dos seus próprios interesses, que por vezes podem estar muito distantes daqueles do teórico.

Nas ocasiões nas quais não se possa verbalizar alguns aspectos da interpretação resultante, podem ser utilizados os meios ostensivos. Por exemplo, a comparação com outras interpretações ou a exegese inter-semiótica, onde outros objetos artísticos colaboram para compreender a interpretação. Às vezes,

\footnotetext{
26 Ver o projeto Open Artist \& Dear Audience de Anu Vehviläinen (Polifonia Research Working Group 2010, p. 30; López-Cano e San Cristóbal, 2014, p. 121) e The Piano Sonata in Contemporary Music: A Practical and Analytical Study de Alessandro Cervino (Polifonia Research Working Group 2010, p. 60; López-Cano e San Cristóbal, 2014, p. 132-133).
} 
a própria performance pode funcionar como espaço de transmissão do conhecimento proposicional como naqueles casos onde se projetam imagens ou texto durante a performance. ${ }^{27}$ Outra maneira de representar o conhecimento tácito da instância artística é a filmagem das reações do público no momento da interpretação. Podem ser incluídas pequenas entrevistas rápidas. Também pode ser utilizada uma nova contextualização da performance proposta: fotos, gravações, filmagens da mesma são intercaladas, divididas em formatos áudio visuais aos quais se acrescenta texto ou voz que expresse algum conteúdo literal ou metafórico, teórico, descritivo ou poético - que se aproxima assintoticamente, sem chegar a tocar o conteúdo que desejo comunicar, conteúdo impossível de dizer explicitamente. Podemos fazer o exercício inverso: ao invés de iniciar com a performance, começar pelo discurso proposicional no qual se acrescentam intervenções de fragmentos da performance que funcionam como argumentos. Podem ser construídas argumentações verbais ou audiovisuais para além das construções teóricas ou criar objetos paralelos que colaborem na experimentação comparativa dos modos de interpretação da mesma música.

\section{Conclusões}

A pesquisa artística em interpretação musical não está gerando novos conhecimentos sobre o mundo, no entanto, tem o potencial de propor transformações profundas no entorno profissional da música. Os desafios maiores que propõe estão em relação aos discursos e produção de conhecimento aceitas pela academia. Em primeiro lugar, os exemplos de casos mencionados nos falam de uma atividade acadêmica que oscila continuamente entre o trabalho técnico e a especulação intelectual mais elaborada. Por outro lado, ao se defrontar continuamente à necessidade de expressar o conhecimento não proposicional, estes casos possibilitam a oportunidade de experimentar formatos e modos gnosiológicos emergentes. A criatividade que se supõe que possuem os praticantes desta modalidade de pesquisa apresenta novos desafios em relação à argumentação audiovisual e digital, alternados continuamente aos modos mais convencionais. Com certeza criarão, com o passar do tempo, seus próprios

27 Ver o projeto Requiem por la muerte del yo artista de Adrián Blanco (López-Cano e San Cristóbal, 2014, p. 191-192) ou Merging cultures: Manga and Classical music de Misaki Yamada (López-Cano e San Cristóbal, 2014, p. 214). Requiem por la muerte del yo artista. Trabalho de conclusão de curso (ESMuC 2013) de Adrián Blanco (Fragmento de pista de vídeo (com som guia) projetado durante a performance ao vivo). Disponível em: https://youtu.be/cWZMF16EytI. Acesso em: 28 maio 2015. 
protocolos de escrita multimídia e rituais acadêmicos. Em breve, saberemos se este modelo de pesquisa resolve ou aprofunda ainda mais algum aspecto da crise da contemporaneidade.

\section{Referencias}

ASPRILLA, Ligia. 2014. La producción de conocimiento desde las artes Propuesta para un Programa Nacional de las Artes adscrito a Colciencias. A contratiempo 23, 2014. Disponível em: http://www.territoriosonoro.org/CDM/acontratiempo/?ediciones/revista23/artculos/la-produccin-de-conocimiento-desde-las-artes-propuesta-para-unprograma-nacional-de-las-artes-adscri.html Acesso em: 22 abr. 2015.

BORGDORFF, Henk. The Conflict of the Faculties. Leiden: Leiden University Press, 2012.

. A Brief Survey of Current Debates on the Concepts and Practices of Research in the Arts. In: WILSON, Mick; van RUITEN, Schelte (Ed.). SHARE Handbook for Artistic Research Education. Amsterdam, Dublin, Gottenburg: SHARE Network, 2013. Disponível em: http://www.eliaartschools.org/images/products/120/share-handbook-for-artistic-researcheducation-high-definition.pdf. Acesso em: 22 abr. 2015.

BOWEN, José Antonio. 2008. La Práctica de la interpretación frente al análisis de la interpretación. ¿Por qué deben estudiar interpretación los intérpretes? Quodlibet, 41, p. 81-97, 2008.

BRIX, Anders. Solid Knowledge: Notes on the Nature of Knowledge Embedded in Designed Artefacts. Artifact v. 2 n. 1, p. 36-40, 2008.

CASTORIADIS, Cornelius. Figuras de lo pensable. Madrid: Cátedra, 1999. 
CLARKE, Eric. Empirical methods in the study of performance. In: CLARKE, Eric; COOK, Nicholas (Ed.). Empirical musicology: Aims, methods, prospects. Oxford: Oxford University Press, 2004, p. 77-102.

COOK, Nicholas. 2010. The Ghost in the Machine: Towards a Musicology of Recordings. Musicae Scientiae v. 14, n. 2, p. 3-21.

DESAIN, Peter; HONING, Henkjan. HONING. The formation of rhythmic categories and metric priming. Perception v. 32, n. 3, p. 341-66, 2003.

GODØY, Rolf Inge; LEMAN, Marc (Ed.). Musical Gestures: Sound, Movement, and Meaning. London; New York: Routledge, 2010.

HASEMAN, Brad. A Manifesto for Performative Research. Media International Australia incorporating Culture and Policy, n. 118, 2006, p. 98-106.

HEIDER, Eleanor Rosch. 1972. Probabilities, sampling, and ethnographic method: The case of Dani colour names. Man, 1972, p. 448-466.

HEIDER, Eleanor Rosch; OLIVIER, Donald C. The structure of the color space in naming and memory for two languages. Cognitive Psychology v. 3, n. 2, 1972, p. 337-354.

HOGARTH, Robin M. Educar la intuición: el desarrollo del sexto sentido. Barcelona: Paidós, 2002.

JOHNSON, Mark. The Body in the Mind: The Bodily Basis of Meaning, Imagination, and Reason. Chicago: University of Chicago Press, 1997.

The Meaning of the Body: Aesthetics of Human Understanding.

Chicago: University of Chicago Press, 2007.

JUSLIN, Patrik N. 2001. Communicating emotion in music performance: A review and a theoretical framework. In: SLOBODA, John; JUSLIN, Patrick (Ed.). Music and emotion: Theory and research. Series in affective science. New York, NY, US: Oxford University Press, 2001, p. 309-337.

LAKOFF, George. Women, Fire, and Dangerous Things: What Categories Reveal about the Mind. Chicago: University of Chicago Press, 1987.

LAKOFF, George; JOHNSON, Mark. Metáforas de la vida cotidiana. Madrid: Cátedra, 1998.

LAURENCE, Stephen; MARGOLIS, Eric. Concepts and cognitive science. In: 3-81. . (Eds.). Concepts: core readings. Cambridge Mass.: MIT Press, 1999, p.

LEECH-WILKINSON, Daniel. Performance Style in Elena Gerhardt's Schubert Song Recordings. Musicae Scientiae v. 14, n. 2, 2010, p. 57-84.

LÓPEZ CANO, Rubén. 2003. Setting de body in music. Gesture, schemata and stylistic-cognitive types. In: International Conference on Music and gesture, University of East Anglia, Norwich, United Kingdom.

. De la Retórica a la Ciencia Cognitiva. Valladolid: Universidad de Valladolid, 2004. Disponível em: www.lopezcano.net.

Performatividad y narratividad musical en la construcción social de género. Una aplicación al Tango queer, Timba, Regetón y Sonideros. In: MUNS, Rubén Gómez (Ed.). Música, ciudades, redes: creación musical e interacción social. Salamanca: SIbE-Fundación Caja Duero, 2008. 
Música, cuerpo, mente extendida y experiencia artística: la gesticulación de Keith Jarret en su Tokyo '84 Encore. VIII Reunión anual de la SACCOM (Sociedad Argentina para las Ciencias Cognitivas de la Música): La experiencia artística y la cognición musical. 25 y 26 de Junio de 2009.

"De la repetition au concert". Explorando la investigación artística multidisciplinar. L'ESMuC digital. Revista de L'Escola Superior de Música de Catalunya, 2013. Disponível em: http://www.esmuc.cat/esmuc digital/Esmucdigital/Revistes/Numero-18-maig-2013/Espai-de-recerca/De-la-repetition-auconcert. Acesso em: 22 abr. 2015.

LÓPEZ-CANO, Rubén; SAN CRISTÓBAL, Úrsula. Investigación artística en música: problemas, métodos, paradigmas, experiencias y modelos. Barcelona: Fonca-Esmuc, 2014. Disponível em: http://invartistic.blogspot.com.es/ Acesso em: 22 abr. 2015.

MARDONES, José María. Filosofía de las ciencias humanas y sociales: materiales para una fundamentación científica. Barcelona: Anthropos, 1991.

MARGOLIS, Eric; LAURENCE, Stephen. Concepts. In: ZALTA, Edward N. (Ed.).The Stanford Encyclopedia of Philosophy, (Spring 2014 Edition), Disponível em: http://plato.stanford.edu/archives/spr2014/entries/concepts/ Acesso em: 22 abr. 2015.

MOLES, Abraham. La Création scientifique. Genève: René Kister, 1957. Tradução espanhola: La creación científica. Madrid: Taurus, 1986.

PALACIOS QUIROZ, Rafael. La pronuntiatio musicale une interprétation rhétorique au service de Händel, Montéclair, C. P. E. Bach et Telemann. París: Université Paris-Sorbonne, 2012.

PEÑALBA, A. El cuerpo en la música a través de la teoría de la Metáfora de Johnson: análisis crítico y aplicación a la música. TRANS Revista Transcultural de Música 9, 2005.

POLIFONIA RESEARCH WORKING GROUP. Researching Conservatoires. Enquiry, Innovation and the Development of Artistic Practice in Higher Music Education (Polifonia Research Working Group). Utrecht: AEC Publications, 2010.

POPPER, Karl. Conocimiento objetivo: un enfoque evolucionista. Madrid: Editorial Tecnos, 1974.

SAN CRISTÓBAL, Úrsula; LÓPEZ-CANO, Rubén. Ars Video. The short music video in early and classical music. L'ESMuC digital. Revista de L'Escola Superior de Música de Catalunya 23, 2013. Disponível em:

http://www.esmuc.cat/esmuc digital/Esmuc-digital/Revistes/Numero-23desembre-2013/Espai-de-recerca. Acesso em: 22 abr. 2015.

SCHACHER, Jan. An Exercise in Freedom. Researching Bodily Performance in Electronic Music. L'ESMuC digital. Revista de L'Escola Superior de Música de Catalunya, v. 21, 2013. Disponível em:

http://www.esmuc.eu/esmuc digital/Esmuc-digital/Revistes/Numero-21octubre-2013/Espai-de-recerca. Acesso em: 22 abr. 2015.

SCHON, Donald A.The Reflective Practitioner: How Professionals Think in Action. New York: Basic Books, 1983.

SMITH, Hazel; DEAN, R. T. Practice-Led Research, Research-Led Practice in the Creative Arts. Edinburgh: Edinburgh University Press, 2009. 
SMITH, Robert. Basso Continuo Realization on the Cello and Viol. Proyecto de Master, Amsterdam: Conservatorio de Amsterdam, 2009.

VARELA, Francisco J.; THOMPSON, Evan; ROSCH, Eleanor. De cuerpo presente: las ciencias cognitivas y la experiencia humana. Barcelona: Gedisa, 1992. 